\title{
Correlation between PET/CT results and histological and immunohistochemical findings in breast carcinomas*
}

\author{
Correlação entre resultado do PET/CT e achados histológicos e imuno-histoquímicos
} em carcinomas mamários

Almir Galvão Vieira Bitencourt ${ }^{1}$, Eduardo Nóbrega Pereira Lima ${ }^{2}$, Rubens Chojniak ${ }^{3}$, Elvira Ferreira Marques ${ }^{4}$, Juliana Alves de Souza ${ }^{5}$, Luciana Graziano ${ }^{5}$, Wesley Pereira Andrade ${ }^{6}$, Cynthia Aparecida Bueno de Toledo Osório ${ }^{7}$

Bitencourt AGV, Lima ENP, Chojniak R, Marques EF, Souza JA, Graziano L, Andrade WP, Osório CABT. Correlation between PET/CT results and histological and immunohistochemical findings in breast carcinomas. Radiol Bras. $2014 \mathrm{Mar} / \mathrm{Abr} ; 47(2): 67-73$.

Abstract Objective: To correlate the results of ${ }^{18} \mathrm{~F}$-fluoro-2-deoxy-D-glucose ( ${ }^{18} \mathrm{~F}$-FDG) positron emission tomography/computed tomography (PET/CT) performed with a specific protocol for assessment of breasts with histological/immunohistochemical findings in breast carcinoma patients.

Materials and Methods: Cross-sectional study with prospective data collection, where patients with biopsy-confirmed breast carcinomas were studied. The patients underwent PET/CT examination in prone position, with a specific protocol for assessment of breasts. PET/CT findings were compared with histological and immunohistochemical data.

Results: The authors identified 59 malignant breast lesions in 50 patients. The maximum diameter of the lesions ranged from 6 to 80 $\mathrm{mm}$ (mean: $32.2 \mathrm{~mm}$ ). Invasive ductal carcinoma was the most common histological type ( $n=47 ; 79.7 \%)$. At PET/CT, 53 (89.8\%) of the lesions demonstrated anomalous concentrations of ${ }^{18} \mathrm{~F}-\mathrm{FDG}$, with maximum SUV ranging from 0.8 to 23.1 (mean: 5.5). A statistically significant association was observed between higher values of maximum SUV and histological type, histological grade, molecular subtype, tumor diameter, mitotic index and Ki-67 expression.

Conclusion: PET/CT performed with specific protocol for assessment of breasts has demonstrated good sensitivity and was associated with relevant histological/immunohistochemical factors related to aggressiveness and prognosis of breast carcinomas.

Keywords: Breast cancer; PET/CT; Histology.

Resumo Objetivo: Correlacionar o resultado da tomografia por emissão de pósitrons/tomografia computadorizada (PET/CT) com ${ }^{18} \mathrm{~F}-$ flúor-2deoxi-D-glicose $\left({ }^{18} \mathrm{~F}-\mathrm{FDG}\right.$ ) realizado com protocolo específico para avaliação das mamas com achados histológicos/imuno-histoquímicos em pacientes com carcinomas mamários.

Materiais e Métodos: Estudo transversal, com coleta prospectiva dos dados, em que foram estudadas pacientes com carcinomas mamários confirmados por biópsia. As pacientes incluídas foram submetidas a exame de PET/CT realizado em decúbito ventral, com protocolo específico para avaliação das mamas. Os achados do PET/CT foram comparados aos dados histológicos e imuno-histoquímicos. Resultados: Foram identificadas 59 lesões mamárias malignas nas 50 pacientes incluídas no estudo. 0 diâmetro máximo das lesões variou de 6 a $80 \mathrm{~mm}$ (média : 32,2 mm). 0 tipo histológico mais comum foi o carcinoma ductal invasivo ( $n=47 ; 79,7 \%$ ). No PET/CT, 53 (89,8\%) destas lesões apresentaram concentração anômala de ${ }^{18}$ F-FDG, com SUV máximo variando de 0,8 a 23,1 (média: 5,5). Houve associação estatisticamente significante entre maiores valores de SUV máximo e tipo histológico, grau histológico, subtipo molecular, diâmetro do tumor, índice mitótico e expressão de Ki-67.

Conclusão: O PET/CT realizado com protocolo específico para avaliação das mamas demonstrou boa sensibilidade e apresentou associação com importantes fatores histológicos/imuno-histoquímicos relacionados à agressividade e prognóstico dos carcinomas mamários. Unitermos: Neoplasias da mama; PET/CT; Histologia.

* Study developed at A.C.Camargo Cancer Center, São Paulo, SP, Brazil.

1. PhD, Titular Physician, Department of Imaging, A.C.Camargo Cancer Center, São Paulo, SP, Brazil.

2. PhD, Physician Responsible for the Unit of Nuclear Medicine at A.C.Camargo Cancer Center, São Paulo, SP, Brazil.

3. PhD, MD, Director, Department of Imaging, A.C.Camargo Cancer Center, São Paulo, SP, Brazil.

4. Physician Responsible for the Unit of Breast Imaging at A.C.Camargo Cancer Center, São Paulo, SP, Brazil.

5. Titular Physicians, Department of Imaging, A.C.Camargo Cancer Center, São Paulo, SP, Brazil.

6. Master, Titular Physician, Department of Mastology, A.C.Camargo Cancer Center, São Paulo, SP, Brazil.

\section{INTRODUCTION}

Breast cancer is the second malignant tumor in incidence and the main cause of cancer deaths among women in Bra$\mathrm{zil}^{(1)}$. However, different molecular subtypes of breast carcinomas may present with different prognosis and therapeutic

7. Master, Titular Physician, Department of Pathology, A.C.Camargo Cancer Center, São Paulo, SP, Brazil.

Mailing Address: Dr. Almir Bitencourt. Rua Professor Antônio Prudente, 211, Liberdade. São Paulo, SP, Brazil, 09015-010. E-mail: almirgvb@yahoo.com.br.

Received March 11, 2013. Accepted after revision December 12, 2013. 
responses. For example, the tumors that express hormone receptors are generally better differentiated and have better prognosis. Several histological and immunohistochemical factors have been taken into consideration in the evaluation of tumors aggressiveness and to classify a tumor into a specific molecular subtype for appropriate therapeutic planning $^{(2)}$. Imaging methods play a fundamental role in the screening, diagnosis and management of breast cancer patients. Because of limitations of conventional imaging methods (mammography and ultrasonography), magnetic resonance imaging (MRI) and new functional imaging methods have been increasingly utilized ${ }^{(3,4)}$.

Positron emission tomography/computed tomography (PET/CT) with ${ }^{18}$ F-fluoro-2-deoxy-D-glucose $\left({ }^{18} \mathrm{~F}\right.$-FDG) has been widely utilized for the diagnosis, staging and restaging of different types of cancer ${ }^{(5-7)}$. Differently from conventional imaging methods capable of detecting only anatomical changes, ${ }^{18}$ F-FDG PET/CT is capable of providing information related to glucose metabolism in the various organs and tissues. However, the ${ }^{18}$ F-FDG uptake by the tumors is variable, depending on the organ of origin and the type of tumor.

For breast cancer patients, ${ }^{18}$ F-FDG PET/CT plays a proven role in the detection of distant metastases, tumor recurrence and evaluation of therapeutic response. However, for the diagnosis of primary breast lesions and locoregional staging, ${ }^{18}$ F-FDG PET/CT has a limited diagnostic value as compared with other imaging methods ${ }^{(8,9)}$. In the literature, ${ }^{18}$ F-FDG PET/CT has demonstrated sensitivity of 64 $96 \%$ and specificity of $73-100 \%$ for the diagnosis of suspicious breast lesions ${ }^{(10)}$. The main limitations of ${ }^{18}$ F-FDG $\mathrm{PET} / \mathrm{CT}$ in the diagnosis of breast lesions are related to low spatial resolution of PET, impairing the identification of lesions smaller than $10 \mathrm{~mm}$. For tumors smaller than $10 \mathrm{~mm}$, the sensitivity of ${ }^{18} \mathrm{~F}$-FDG PET/CT is $25 \%$, while for tumors between $10 \mathrm{~mm}$ and $20 \mathrm{~mm}$ the sensitivity is $84 \%{ }^{(11)}$. The ${ }^{18} \mathrm{~F}$-FDG uptake is also lower in noninvasive tumors such as ductal carcinoma in situ (DCIS) or in slow-growth tumors such as tubular carcinoma. Additionally, ${ }^{18}$ F-FDG $\mathrm{PET} / \mathrm{CT}$ is less sensitive for the diagnosis of invasive lobular carcinoma (ILC) in relation to invasive ductal carcinoma (IDC) $)^{(9,12)}$.

The purpose of this study was to correlate the results of ${ }^{18}$ F-FDG PET/CT performed according to a specific protocol for the evaluation of breasts with histological and immunohistochemical findings in patients with breast carcinoma.

\section{MATERIALS AND METHODS}

Cross-sectional, unicenter study, with prospective data collection, involving patients with biopsy-confirmed breast carcinomas. Prior to the data collection, the study was approved by the Committee for Ethics in Research of the institution.

Patients presenting with suspicious breast lesions and formal indication for biopsy, whether percutaneous or sur- gical, in the period between May 2010 and January 2012, were invited to participate in the study. After agreement and signature of a term of free and informed consent, the patients underwent ${ }^{18} \mathrm{~F}$-FDG $\mathrm{PET} / \mathrm{CT}$ performed according to a specific protocol for the present study, before the collection of material for the histopathological study.

Exclusion criteria were the following: patients with breast lesions smaller than $5 \mathrm{~mm}$; patients submitted to breast biopsy up to 15 days before PET/CT; patients undergoing radiotherapy or chemotherapy and those who had received the last treatment dose less than 30 days before PET/CT; pregnant or breastfeeding women; and those patients whose biopsy results were compatible with benign lesions.

The study sample included 50 patients with ages ranging from 29 to 75 years (mean 47.4 years; standard deviation 11.3 years). Family history of breast cancer was present in 18 patients $(35.0 \%)$ and only 3 patients $(6.0 \%)$ had a previous diagnosis of breast cancer.

The PET/CT exams were performed with a dedicated Philips Gemini PET/CT apparatus after ${ }^{18}$ F-FDG injection $(0.154 \mathrm{mCi} / \mathrm{kg}$ of weight $)$, under fasting conditions and muscular rest. Before ${ }^{18}$ F-FDG administration, capillary blood glucose level to ensure glucose serum levels $<150$ $\mathrm{mg} / \mathrm{dl}$. Images acquisition was initiated in the interval between 60 and 120 minutes after the dose administration. The PET/CT images acquisition was performed according to the standard protocol for oncologic evaluation consisting of whole body imaging with the patient in dorsal decubitus. Subsequently, a special images sequence was acquired exclusively for the evaluation of the breasts, covering the chest region and the axillae, with the patient in ventral decubitus with the breasts hanging freely, allowing the complete visualization of the breast parenchyma. For the PET/CT images acquisition for breast evaluation a device was especially made, reproducing the shape of the coil utilized in breast MRI (Figure 1). The cephalocaudal acquisition initiates with contiguous tomographic $2.5 \mathrm{~mm}$-thick sections performed in the two-channel helical system without the utilization of intravenous contrast agent, followed by the acquisition of the ${ }^{18}$ F-FDG images by the coupled PET. Each $15 \mathrm{~cm}$ axial field of view bed position was acquired with acquisition time of 90 seconds.

The interpretation and evaluation of the ${ }^{18}$ F-FDG PET/ CT images were performed by at least two experienced nuclear medicine physicians. The areas with increased ${ }^{18} \mathrm{~F}$ FDG uptake in relation to normal breast parenchyma were considered as positive, and the calculation of maximum SUV was made for each region of interest. For data analysis, one considered only the maximum SUV measured on the breast PET/CT images acquired in ventral decubitus. The PET/ CT findings were compared with histological and immunohistochemical data.

The histological data were obtained from reports provided by the Anatomical Pathology Department of the hospital. The following morphological and immunohistochemi- 

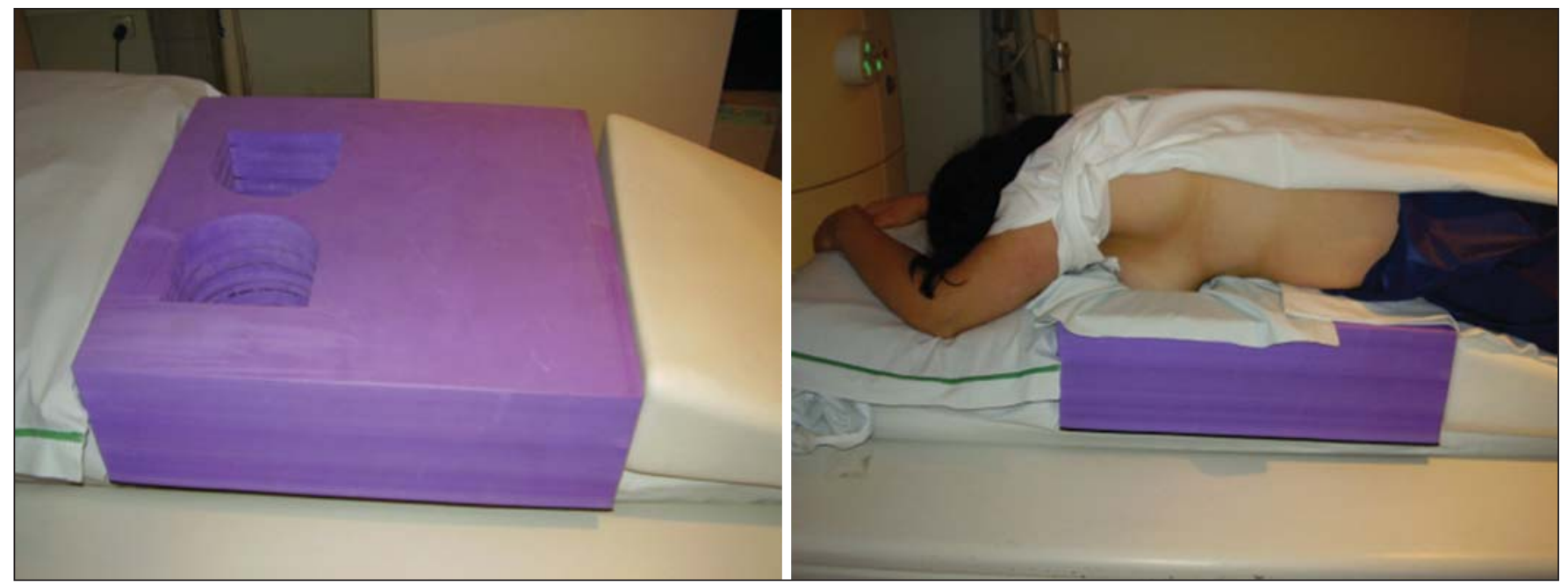

Figure 1. Device constructed to perform PET/CT with the patient in ventral decubitus and with her breasts hanging freely.

cal parameters were observed: histological type, histological grade, nuclear grade, mitotic index, estrogen and progesterone hormone receptors and Her-2 and Ki-67 expression. As the immunohistochemical profile was considered, breast carcinomas were classified into four molecular subtypes, as follows: luminal A (positive for estrogen and/or progesterone receptor, with low expression of cell proliferation markers); luminal B (positive for estrogen and/or progesterone receptor, with overexpressed Her-2 or high expression of cell proliferation markers); Her-2 (negative for hormone receptors and overexpressed Her-2); and triple negative (negative for hormone and Her-2 receptors).

All the obtained data were stored in a databank for statistical analysis by means of the SPSS release 20.0. The descriptive analysis of categorical variables comprised the calculation of simple and relative frequencies. The numeric variables were described as mean, standard deviation (SD), minimum and maximum. In the statistical analysis the Student's $t$ test was utilized (or the Mann Whitney non-parametric test, as indicated) for comparison of scalar variables between two groups. In the case of three or more groups, the variance analysis test or the Kruskal-Wallis non-parametric test were utilized. The comparison between two continuous variables was performed by means of linear correlation and dispersion charts. For the study of categorical variables, $2 \times 2$ and $2 \times 3$ tables were utilized, with evaluation of statistical significance by means of the Pearson's chi-squared test with Yates correction for continuity or the Fisher's exact test, as indicated. Those results with probability of type I error $\leq 5 \%(p \leq 0.05)$ were considered as being statistically significant.

\section{RESULTS}

In the present study, 59 malignant breast lesions were identified in the 50 patients. The maximum lesion diameter ranged from 6 to $80 \mathrm{~mm}$, with a mean diameter of $32.2 \mathrm{~mm}$ (SD $18.4 \mathrm{~mm}$ ). The histological analysis was performed by means of percutaneous biopsy in 32 lesions $(54.2 \%)$ and surgical resection in 27 lesions $(45.8 \%)$. The most common histological type was IDC ( $n=47 ; 79.7 \%)$, followed by ILC $(n=6 ; 10.2 \%)$, mucinous carcinoma $(n=2 ; 3.4 \%)$, DCIS $(n=2 ; 3.4 \%)$ and Paget's disease $(n=2 ; 3.4 \%)$. Breast carcinomas histological and immunohistochemical characteristics are described on Table 1.

Table 1-Histological and immunohistochemical characteristics of breast carcinomas $(n=59)$

\begin{tabular}{lcc}
\hline Characteristic & $n$ & Percentage \\
\hline Histological grade $(n=51)$ & & \\
I & 7 & $13.7 \%$ \\
II & 22 & $43.1 \%$ \\
III & 22 & $43.1 \%$ \\
Nuclear grade $(n=54)$ & & \\
I & 3 & $5.6 \%$ \\
II & 12 & $22.2 \%$ \\
III & 39 & $72.2 \%$ \\
Molecular subtype $(n=58)$ & & \\
Luminal A & 17 & $29.3 \%$ \\
Luminal B & 27 & $46.6 \%$ \\
Her-2 & 5 & $8.6 \%$ \\
Triple-negative & 9 & $15.5 \%$ \\
Ki-67 expression $(n=54)$ & & \\
$\leq 15 \%$ & 17 & $31.5 \%$ \\
$>15 \%$ & 37 & $68.5 \%$ \\
\hline
\end{tabular}

At PET/CT, $53(89.8 \%)$ of the lesions presented with anomalous ${ }^{18}$ F-FDG uptake, and maximum SUVs ranged from 0.8 to 23.1 (mean 5.5; SD 5.0). Figures 2 and 3 show PET/CT images of positive breast carcinomas. Six lesions $(10.2 \%)$ did not present anomalous ${ }^{18} \mathrm{~F}$-FDG uptake, thus being considered as false-negative results, and three out of them had diameters $<10 \mathrm{~mm}$ while the largest lesion presented a maximum diameter of $15 \mathrm{~mm}$. At immunohistochemical analysis, all the tumors with false-negative results at PET/CT were positive for hormone receptors. 


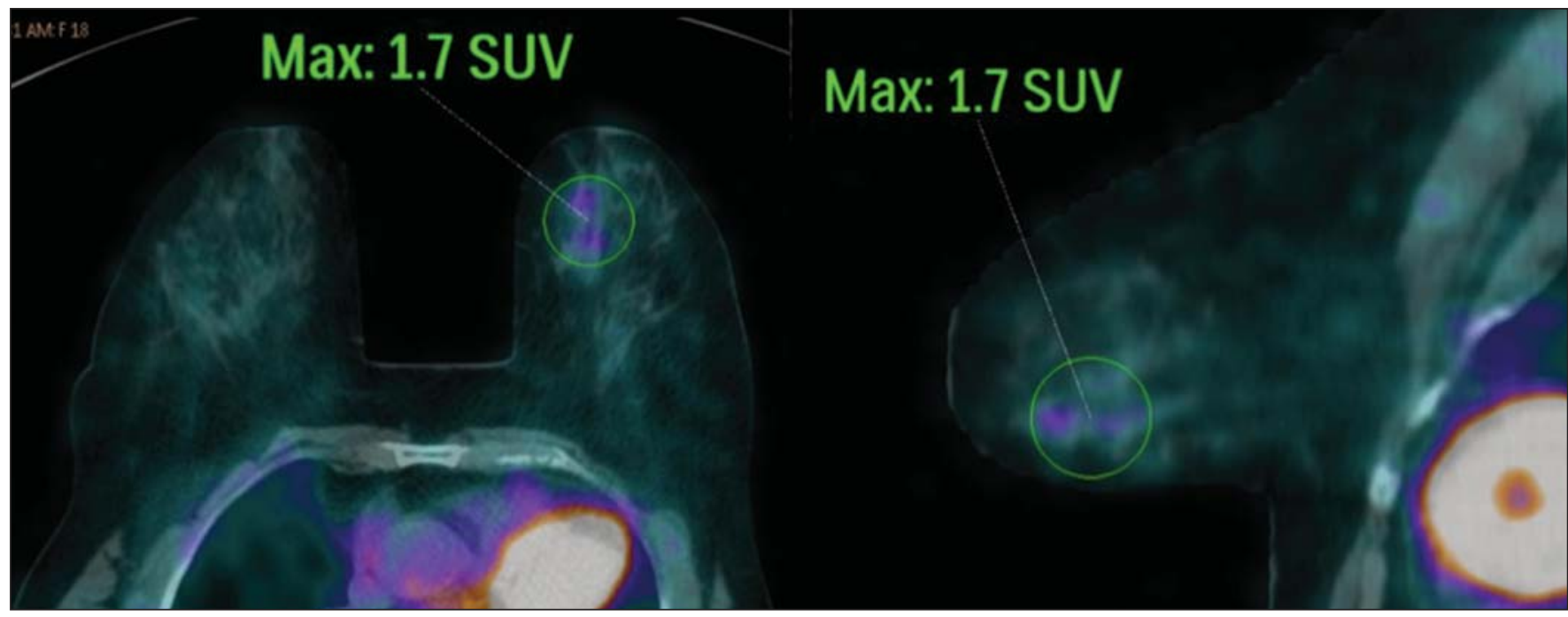

Figure 2. A 63-year-old female patient with ductal carcinoma in situ located in the inferomedial quadrant of her left breast. Axial and sagittal breast-dedicated PET/ CT images demonstrating slightly increased FDG uptake on the lesion's topography in the left breast (maximum SUV: 1.7).

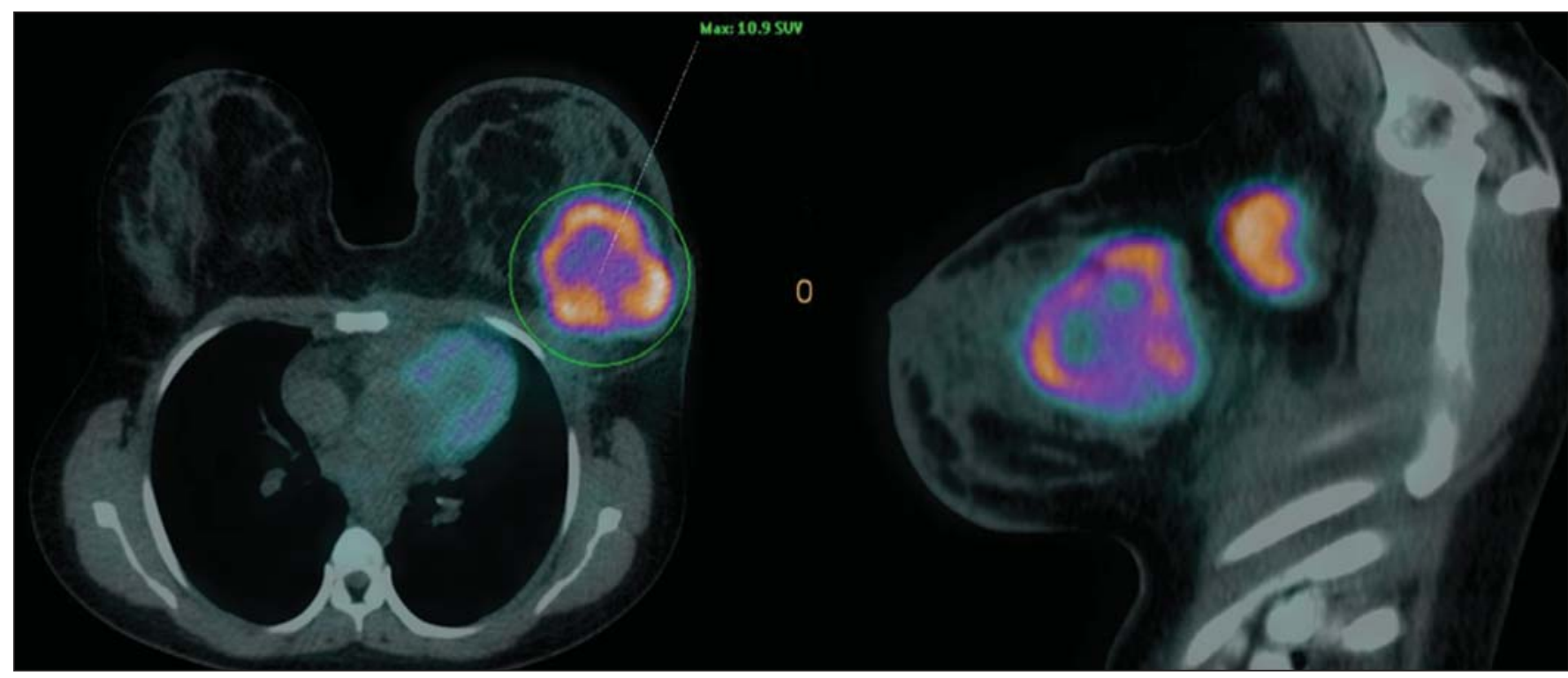

Figure 3. A 42-year-old female patient with invasive ductal carcinoma (triple-negative subtype) in the superolateral quadrant of her left breast in association with axillary lymph node enlargement and diffuse skin thickening in that breast (inflammatory tumor). Axial and sagittal breast-dedicated PET/CT images demonstrating heterogeneously increased FDG uptake on the mass topography in the left breast (maximum SUV: 10.9) and in the enlarged axillary lymph node (maximum SUV: 11.2).

Histological grade, nuclear grade and Ki-67 expression were the histological/immunohistochemical factors of breast carcinomas which presented with statistically significant association with positive results at PET/CT. All tumors which did not express hormone receptors (subtypes Her-2 and triplenegative) were positive at PET/CT. Histological/immunohistochemical factors associated with higher maximum SUV values in malignant lesions were the following: histological type, molecular subtype, tumor diameter, mitotic index and Ki-67 expression (Table 2, Figures 4, 5 and 6).

\section{DISCUSSION}

The results of the present study demonstrate that PET/ CT performed in ventral decubitus, with a specific protocol for breast evaluation, has high sensitivity for the diagnosis of breast carcinomas, and is positive in approximately $90 \%$ of the cases of malignant tumors.

Since 1999, when Yutani et al. first described the utilization of PET with the patient in ventral decubitus, several authors demonstrated the advantages of such positioning in the evaluation of breast lesions ${ }^{(13)}$. In the prone position, PET/CT increases the detection of breast cancer because of higher contrast between tumor-like and non-tumor-like tissues and higher SUV values presented by breast tumors in this acquisition modality, as compared with PET performed in the supine position, increasing the observer's confidence in the evaluation of areas of abnormal metabolism ${ }^{(13-15)}$.

The spatial resolution of the method was the main limitation observed in the present study, considering the PET equipment currently available in the market. Six false-nega- 
Table 2 - Correlation between histological/immunohistochemical factors and maximum SUV value of breast carcinomas $(n=59)$.

\begin{tabular}{lccc}
\hline & \multicolumn{2}{c}{ Maximum SUV } & \\
\cline { 2 - 3 } & Mean & Standard deviation & $p$ \\
\hline Histological type & & & \\
$\quad$ Invasive ductal carcinoma & 6.3 & 5.3 & 0.005 \\
$\quad$ Others & 2.2 & 1.5 & \\
Histological grade & & & \\
I & 1.6 & 1.1 & 0.001 \\
II & 4.2 & 3.7 & \\
III & 8.1 & 5.8 & \\
Nuclear grade & & & \\
I & 1.4 & 1.2 & \\
II & 4.3 & 3.5 & \\
III & 5.4 & 5.0 & \\
Molecular subtype & & & \\
$\quad$ Luminal A & 3.5 & 3.5 & \\
Luminal B & 4.9 & 3.9 & \\
Her-2 & 4.8 & 3.7 & \\
Triple-negative & 11.9 & 6.7 & \\
\hline
\end{tabular}

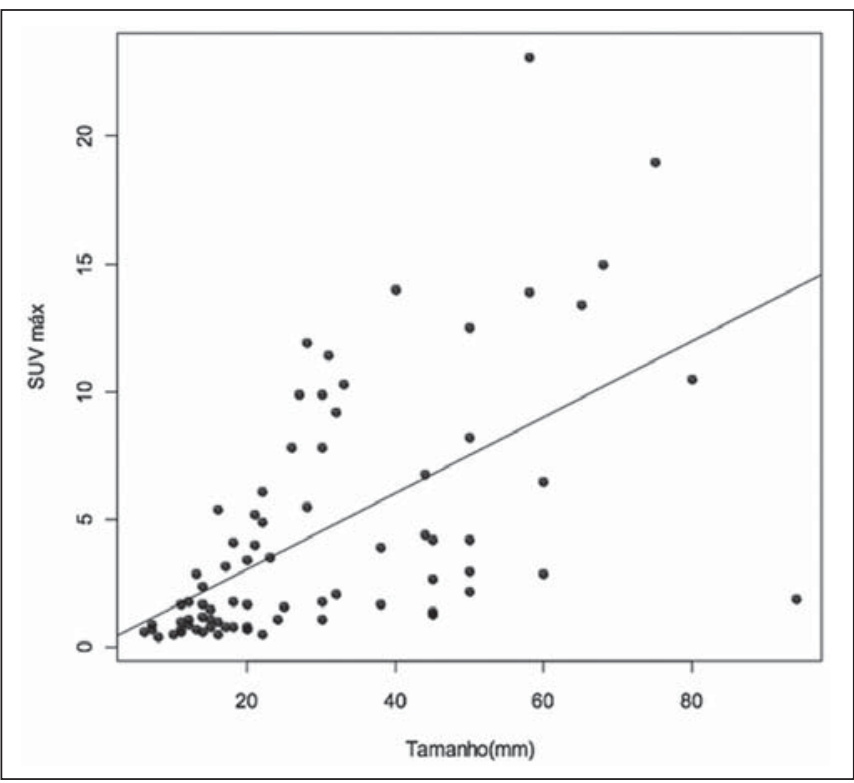

Figure 4. Dispersion chart demonstrating correlation between maximum SUV value and the largest diameter of breast carcinomas $(n=59)$. It is expected that maximum SUV increases in 0.14 for every $1 \mathrm{~mm}$ increment in tumor diameter ( $p$ $<0.0001)$.

tive results were observed and in three of them, the diameter was $<10 \mathrm{~mm}$, while the largest tumor had a $15 \mathrm{~mm}$ in diameter. In the present study, all the false-negative lesions at PET/CT were identified at MRI. Several authors had already demonstrated the lower sensitivity of PET for lesions $<10 \mathrm{~mm}^{(16,17)}$. Kumar et al., for example, have correlated clinical and pathological factors associated with PET results in breast lesions and found that small $(\leq 10 \mathrm{~mm})$ and low grade tumors are strong predictors of false-negative results ${ }^{(16)}$.

Some authors have attempted to establish a cut-off point for the maximum SUV value to differentiate benign from

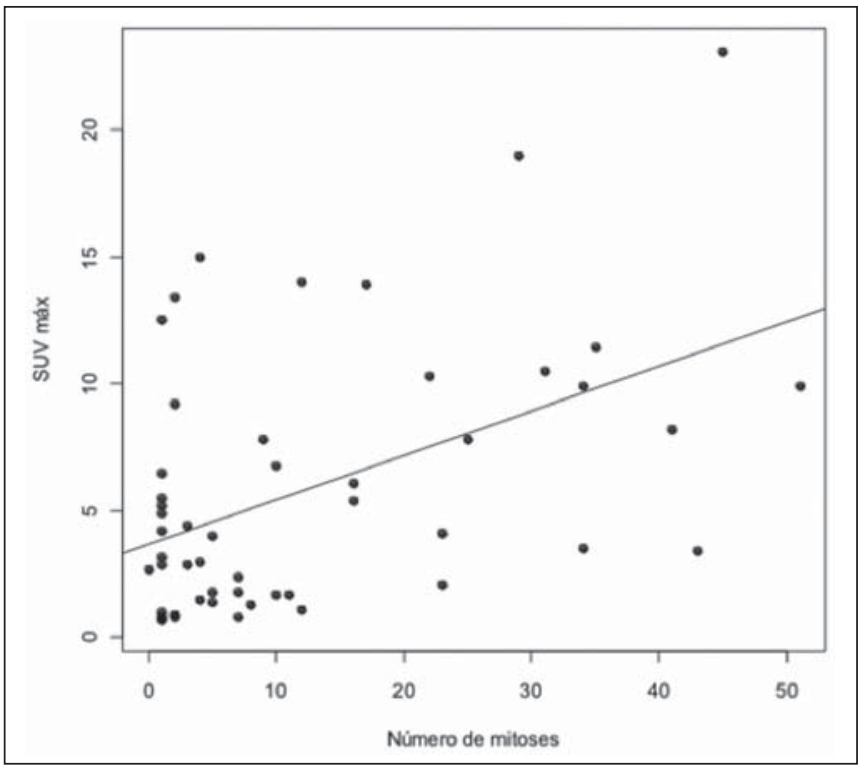

Figure 5. Dispersion chart demonstrating correlation between maximum SUV value and the mitotic index in the breast carcinomas $(n=59)$. It is expected that the maximum SUV increases on 0.17 for each unit increment in the number of mitoses $(p=0.0005)$.

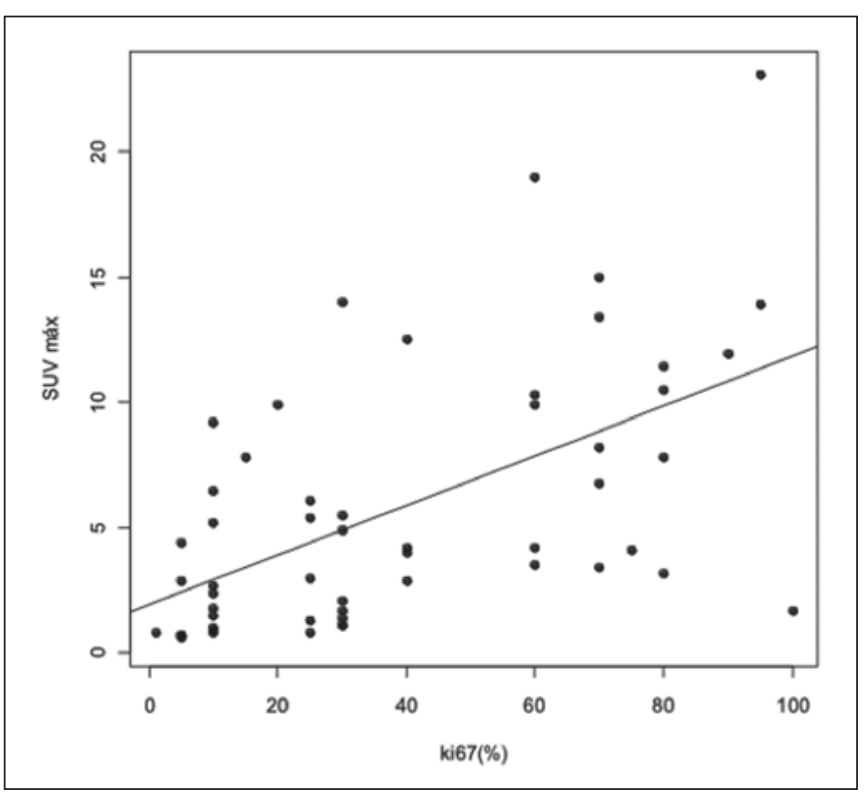

Figure 6. Dispersion chart demonstrating correlation between maximum SUV value and Ki-67 expression in breast carcinomas $(n=59)$. It is expected that the maximum SUV increases in 0.09 for every $1 \%$ increment in the Ki-67expression $(p<0.0001)$

malignant breast lesions ${ }^{(18)}$. However, most studies have demonstrated that considering any cut-off point, many diagnoses would be missed because of low SUV values presented by some types of breast carcinomas, particularly low grade tumors ${ }^{(15,19)}$. Thus, most current studies consider that all lesions with ${ }^{18}$ F-FDG uptake above that of normal tissue should be considered suspicious. In such cases, it is fundamental to correlate conventional imaging studies, clinical data and histological results, as necessary, to rule out possible falsepositive results, which may be related to acute or chronic inflammatory processes, breastfeeding, benign lesions (fibro- 
cystic changes, fibroadenomas, etc.), silicone granulomas, fat necrosis and postoperative/actinic changes ${ }^{(20)}$.

As demonstrated by other authors, the present study confirms that PET has the potential to identify more aggressive breast tumors as well as their prognostic implications, and may be a useful tool for predicting the biological characteristics of the tumor before treatment. The following factors were associated with higher maximum SUV values in malignant lesions: histological type and grade, molecular subtype, tumor diameter, mitotic index and Ki-67 expression. As regards histological type, IDCs presented SUV values above the combination of the other carcinomas found in the present study's sample (mucinous carcinoma, ILC, DCIS and Paget's disease).

Regarding the molecular subtype, it is important to highlight that all tumors negative for hormone receptors (subtypes Her-2 and triple negative) presented anomalous ${ }^{18} \mathrm{~F}$ FDG uptake at PET/CT. Such results are in agreement with those reported by other studies in the literature ${ }^{(21-23)}$. Lessdifferentiated tumors without hormone receptors are more aggressive and have a more accelerated glucose metabolism to supply the rapid growth demand. Basu et al. have found a $100 \%$ PET sensitivity in breast cancers of "triple-negative" subtype, and greater ${ }^{18} \mathrm{~F}$-FDG uptake in this subtype as compared with the subtypes with positive hormone receptors. Those authors have suggested that PET/CT may be an important marker for tumor activity and treatment response in such tumors $^{(21)}$.

Ueda et al. have assessed 152 breast cancer patients and, at multivariate analysis, found that the invasive tumor size, nuclear grade and negativity for estrogen receptor were associated with higher SUV values ${ }^{(22)}$. Mavi et al. have also demonstrated that breast tumors negative for estrogen receptors have maximum SUV values significantly higher than those positive for estrogen receptors. In that same study, the authors have found 25 tumors $>5 \mathrm{~mm}$ in the surgical specimens which did not present increased ${ }^{18}$ F-FDG uptake, and all of such tumors were positive for hormone receptors ${ }^{(23)}$. In the present study the authors could observe that all falsenegative PET/CT results were positive for hormone receptors (luminal A and luminal B subtypes).

Several methods are being developed to improve the current results of ${ }^{18} \mathrm{~F}$-FDG PET/CT in the diagnosis of breast lesions. For example, in the last years a specific and dedicated apparatus was developed for acquisition of three-dimensional breast ${ }^{18}$ F-FDG PET/CT images under slight compression, and in the same planes as in mammography. This new imaging modality called positron emission mammography (PEM) presents the following main advantages in relation to $\mathrm{PET/CT}$ : high spatial resolution, being capable of identifying lesions as small as $2 \mathrm{~mm}$; correlation with mammographic images; and possibility of guiding percutaneous biopsies ${ }^{(24)}$. Such a method has demonstrated high diagnostic accuracy for primary breast lesions, including carcinomas in situ, with sensitivity and specificity of up to
$91 \%$ and $93 \%$ respectively ${ }^{(25,26)}$. PEM has also demonstrated to be useful in the preoperative evaluation of breast tumors, with results similar to those of $\mathrm{MRI}^{(27)}$.

Additionally to increased spatial resolution, new and more specific markers for breast cancer are being developed to overcome ${ }^{18} \mathrm{~F}$-FDG PET/CT results, considering the poor ${ }^{18}$ F-FDG specificity. Among these new markers one should highlight ${ }^{18} \mathrm{~F}$-16-alpha-17-beta-fluoroestradiol and ${ }^{68} \mathrm{Ga}$ trastuzumab, which can non-invasively depict the tumor expression of estrogen and Her 2 receptors, respectively, with potential to be useful in the assessment of therapeutic planning and response ${ }^{(28)}$.

It is important to highlight that, with the current technology, PET/CT should not be utilized as the first imaging method for breast cancer diagnosis yet, and the establishment of the therapeutic approach will always depend on histological and immunohistochemical analysis.

\section{CONCLUSION}

The ${ }^{18}$ F-FDG PET/CT study performed under specific protocol for breast assessment has good sensitivity for the diagnosis of breast carcinomas, allowing for the identification of most aggressive tumors at histological analysis. The authors of the present study observed statistically significant association between maximum SUV values and relevant histological and immunohistochemical factors related to breast carcinomas aggressiveness and prognosis. The authors believe that the method is potentially useful for a more effective management of breast lesions, in the near future, with the improvement of spatial resolution of the PET apparatuses and the introduction of new radiopharmaceuticals.

\section{REFERENCES}

1. Brasil. Ministério da Saúde. Instituto Nacional de Câncer. Câncer: incidência de câncer no Brasil. Rio de Janeiro: INCA; 2012.

2. Cirqueira MB, Moreira MAR, Soares LR, et al. Subtipos moleculares do câncer de mama. Femina. 2011;39:499-503.

3. Marques EF, Medeiros MLL, Souza JA, et al. Indicações de ressonância magnética das mamas em um centro de referência em oncologia. Radiol Bras. 2011;44:363-6.

4. Barra FR, Barra RR, Barra Sobrinho A. Novos métodos funcionais na avaliação de lesões mamárias. Radiol Bras. 2012;45:340-4.

5. Soares Junior J, Fonseca RP, Cerci JJ, et al. Lista de recomendações do exame PET/CT com ${ }^{18}$ F-FDG em oncologia. Consenso entre a Sociedade Brasileira de Cancerologia e a Sociedade Brasileira de Biologia, Medicina Nuclear e Imagem Molecular. Radiol Bras. 2010;43:255-9.

6. Curioni OA, Souza RP, Amar A, et al. Valor da PET/CT na abordagem do câncer de cabeça e pescoço. Radiol Bras. 2012;45:315-8.

7. Mohan K, McShane J, Page R, et al. Impact of ${ }^{18}$ F-FDG PET scan on the prevalence of benign thoracic lesions at surgical resection. Radiol Bras. 2011;44:279-82.

8. Groheux D, Espié M, Giacchetti S, et al. Performance of FDG $\mathrm{PET} / \mathrm{CT}$ in the clinical management of breast cancer. Radiology. 2013;266:388-405.

9. Lim HS, Yoon W, Chung TW, et al. FDG PET/CT for the detection and evaluation of breast diseases: usefulness and limitations. Radiographics. 2007;27 Suppl 1:S197-213.

10. Scheidhauer K, Walter C, Seemann MD. FDG PET and other 
modalities in the primary diagnosis of suspicious breast lesions. Eur J Nucl Med Mol Imaging. 2004;31 Suppl 1:S70-9.

11. Avril N, Rosé CA, Schelling M, et al. Breast imaging with positron emission tomography and fluorine-18 fluorodeoxyglucose: use and limitations. J Clin Oncol. 2000;18:3495-502.

12. Crippa F, Seregni E, Agresti R, et al. Association between [18F]fluorodeoxyglucose uptake and postoperative histopathology, hormone receptor status, thymidine labelling index and p53 in primary breast cancer: a preliminary observation. Eur J Nucl Med. 1998;25:1429-34.

13. Yutani K, Tatsumi M, Uehara T, et al. Effect of patients' being prone during FDG PET for the diagnosis of breast cancer. AJR Am J Roentgenol. 1999;173:1337-9.

14. Moy L, Noz ME, Maguire GQ Jr, et al. Prone mammoPET acquisition improves the ability to fuse MRI and PET breast scans. Clin Nucl Med. 2007;32:194-8.

15. Kaida H, Ishibashi M, Fujii T, et al. Improved detection of breast cancer on FDG-PET cancer screening using breast positioning device. Ann Nucl Med. 2008;22:95-101.

16. Kumar R, Chauhan A, Zhuang H, et al. Clinicopathologic factors associated with false negative FDG-PET in primary breast cancer. Breast Cancer Res Treat. 2006;98:267-74.

17. Moy L, Noz ME, Maguire GQ Jr, et al. Role of fusion of prone FDG-PET and magnetic resonance imaging of the breasts in the evaluation of breast cancer. Breast J. 2010;16:369-76.

18. Chae EY, Cha JH, Kim HH, et al. Analysis of incidental focal hypermetabolic uptake in the breast as detected by 18F-FDG PET/ CT: clinical significance and differential diagnosis. Acta Radiol. 2012;53:530-5.

19. Mavi A, Urhan M, Yu JQ, et al. Dual time point 18F-FDG PET imaging detects breast cancer with high sensitivity and correlates well with histologic subtypes. J Nucl Med. 2006;47:1440-6.

20. Adejolu M, Huo L, Rohren E, et al. False-positive lesions mimick- ing breast cancer on FDG PET and PET/CT. AJR Am J Roentgenol. 2012;198:W304-14.

21. Basu S, Chen W, Tchou J, et al. Comparison of triple-negative and estrogen receptor-positive/progesterone receptor-positive/HER2negative breast carcinoma using quantitative fluorine-18 fluorodeoxyglucose/positron emission tomography imaging parameters: a potentially useful method for disease characterization. Cancer. 2008;1 12:995-1000.

22. Ueda S, Tsuda H, Asakawa H, et al. Clinicopathological and prognostic relevance of uptake level using 18F-fluorodeoxyglucose positron emission tomography/computed tomography fusion imaging (18F-FDG PET/CT) in primary breast cancer. Jpn J Clin Oncol. 2008;38:250-8.

23. Mavi A, Cermik TF, Urhan M, et al. The effects of estrogen, progesterone, and C-erbB-2 receptor states on 18F-FDG uptake of primary breast cancer lesions. J Nucl Med. 2007;48:1266-72.

24. Zaidi H, Thompson C. Evolution and developments in instrumentation for positron emission mammography. PET Clin. 2009;4:31727.

25. Berg WA, Weinberg IN, Narayanan D, et al. High-resolution fluorodeoxyglucose positron emission tomography with compression ("positron emission mammography") is highly accurate in depicting primary breast cancer. Breast J. 2006;12:309-23.

26. Narayanan D, Madsen K, Kalinyak JE, et al. Interpretation of positron emission mammography: feature analysis and rates of malignancy. AJR Am J Roentgenol. 201 1;196:956-70.

27. Schilling K, Narayanan D, Kalinyak JE, et al. Positron emission mammography in breast cancer presurgical planning: comparisons with magnetic resonance imaging. Eur J Nucl Med Mol Imaging. 2011;38:23-36.

28. Pinker K, Bogner W, Gruber S, et al. Molecular imaging in breast cancer - potential future aspects. Breast Care (Basel). 2011;6:1109. 